Check for updates

Cite this: Mater. Chem. Front., 2020, 4, 2023

Received 2nd March 2020,

Accepted 20th May 2020

DOI: $10.1039 / \mathrm{d0qm} 00118$

rsc.li/frontiers-materials

\section{Exciton-band tuning induced by the width of the cation in 2D lead iodide perovskite hybrids $\uparrow$}

\begin{abstract}
Marie-Hélène Tremblay, ${ }^{a}$ John Bacsa, ${ }^{a b}$ Stephen Barlow (D) ${ }^{a}$ and Seth R. Marder*a
It was previously demonstrated that the exciton energy of $2 \mathrm{D}$ hybrid organic-inorganic $\mathrm{A}_{2} \mathrm{Pbl}_{4}$ perovskites is correlated with the $\mathrm{Pb}-\mathrm{I}-\mathrm{Pb}$ bond angle of the inorganic layer. We demonstrate that this angle can be tuned by changing the width of the cation and that the exciton band energy can be varied over ca. $100 \mathrm{meV}$, at least within a limited series of $\mathrm{A}_{2} \mathrm{Pbl}_{4}$ compounds where $\mathrm{A}$ is a 2-(3,5-disubstitutedphenyl)ethylammonium or 2-(3-substitutedphenyl)ethylammonium ion and where the substituents are $\mathrm{H}, \mathrm{F}, \mathrm{Cl}, \mathrm{Br}$, or Me. Seven new crystal structures are presented here.
\end{abstract}

\section{Introduction}

Recently, two-dimensional (2D) hybrid organic inorganic perovskites (HOIP) have been used as the active layer for solar cells $^{1-10}$ and light emitting diodes. ${ }^{11,12}$ Compared with their 3D counterparts (such as $\mathrm{MAPbI}_{3}$, where $\mathrm{MA}=$ methylammonium), they can offer superior stability and a much wider structural diversity, since the cation size is not limited by the volume of the cuboctahedral cavity in the 3D inorganic lattice. The optical properties of the perovskite can be tuned by different methods, for example, by changing the connectivity of the octahedra ${ }^{13}$ or the halide ${ }^{14-16}$ used. The optical characteristics of these materials are particularly relevant to solar-cell and light-emitting diode applications. Previous work, both computational ${ }^{17,18}$ and experimental, ${ }^{19}$ on 3D lead iodide structures showed a relationship between the $\mathrm{Pb}-\mathrm{I}-\mathrm{Pb}$ bond angles and the onset of the optical absorption of the material. ${ }^{20-24}$ On increasing the size of the cation $\left(\mathrm{Cs}^{+}<\mathrm{MA}^{+}<\mathrm{FA}^{+}\right.$, where $\mathrm{FA}=$ formamidinium), the $\mathrm{Pb}-\mathrm{I}-\mathrm{Pb}$ angle decreases due to more distortion of the network of $\mathrm{PbI}_{6}$ octahedra, resulting in poorer $\mathrm{Pb}-\mathrm{Hal}$ orbital overlap and an increased band gap. ${ }^{25,26}$ In $2 \mathrm{D} \mathrm{A}_{2} \mathrm{MX}_{4}(\mathrm{~A}=$ organic cation, $\mathrm{M}=$ metal, $\mathrm{X}=$ halide) HOIPs, there is considerably more pronounced excitonic character than in their 3D counterparts. However, trends in the exciton energy often closely follow those in the band gap. Moreover, in some instances, the exciton

\footnotetext{
${ }^{a}$ School of Chemistry and Biochemistry, and Center for Organic Photonics and Electronics (COPE), Georgia Institute of Technology GA, Atlanta 30332-0400, USA. E-mail: seth.marder@chemistry.gatech.edu

${ }^{b}$ Crystallography Lab, Emory University, 201 Dowman Drive, Atlanta, GA, 30322, USA

$\dagger$ Electronic supplementary information (ESI) available: Experimental procedures and crystallographic details; additional figures showing structural features. CCDC 1986784-1986789 and 1987208. For ESI and crystallographic data in CIF or other electronic format see DOI: 10.1039/d0qm00118j
}

energy has been found to also be correlated with the $\mathbf{M}-\mathrm{I}-\mathbf{M}$ angle. ${ }^{8,27-31}$ The steric bulk of the cation has also been found to correlate with the $\mathrm{Sn}-\mathrm{I}-\mathrm{Sn}$ angle in some studies of $\mathrm{A}_{2} \mathrm{SnI}_{4}$ perovskites. $^{23,32,33}$

Knowing that the M-I-M angle correlates with the properties of the material, we were interested to probe whether the width of 2-arylethylammonium cations (defined as the distance between meta and meta ${ }^{\prime}$ substituents) was related to this bond angle. We report the synthesis and crystal growth of a series of 2D perovskites where the aryl group have different widths; the meta substituents on phenylethylammonium (PEA) are systematically changed in the series (dY-PEA) ${ }_{2} \mathrm{PbI}_{4}$ where $\mathrm{Y}=\mathrm{H}, \mathrm{F}, \mathrm{Cl}, \mathrm{Br}$ and $\mathrm{Me}$ (Fig. 1). We describe the structural and optical properties of these materials and compare them to those of other $\mathrm{A}_{2} \mathrm{PbI}_{4}$ species reported in the literature.

\section{Results and discussion}

We investigated the structure and optical characteristics of lead iodide HOIPs with aromatic cations of increasing width. The width, defined here as the Y..Y distance, is incrementally enlarged by adding substituents at the 3,5-position of the PEA ring. The synthesis of the different cations is presented in the ESI. $\dagger$ The HOIPs were crystallized as pale to dark orange plates from a 1:2 solution of $\mathrm{PbI}_{2}$ and $\mathrm{A}^{+} \mathrm{I}^{-}$in $\mathrm{HI} / \mathrm{MeOH}$ (see ESI $\dagger$ for detailed synthesis). We abbreviate these HOIPs as PEA (2-phenylethylammonium), dF-PEA (2-(3,5-difluorophenyl)ethylammonium), dCl-PEA (2-(3,5-dichlorophenyl)ethylammonium), dBr-PEA (2-(3,5-dibromophenyl)ethylammonium), and dMe-PEA (2-(3,5-dimethylphenyl)ethylammonium). Or course, the increase of halogen atom size also results in an increase in polarizability, whereas dMe-PEA has approximately the same width as dBr-PEA, but is anticipated to be less polarizable. The purity of the crystals 

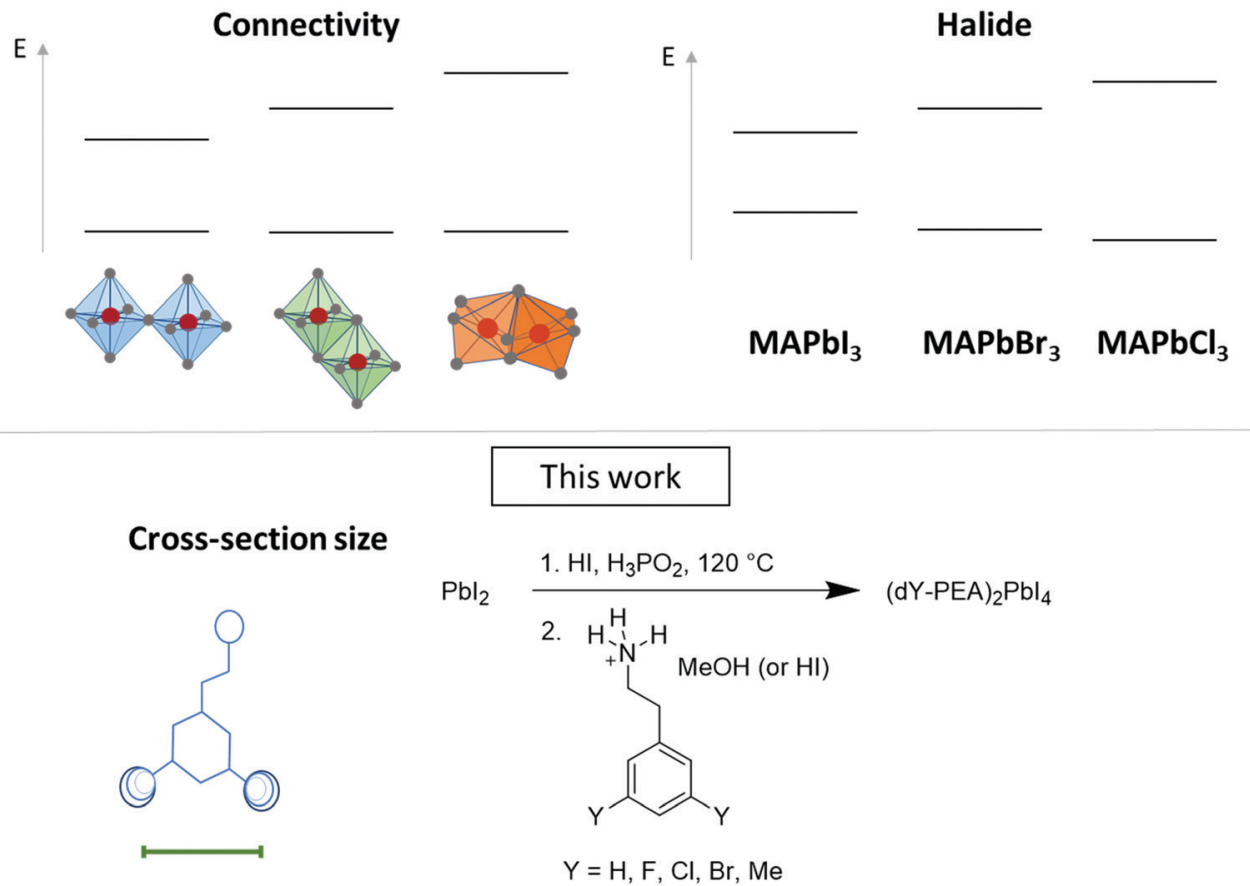

Fig. 1 Top: Approaches to tuning the band energies of HOIPs. Trends in both excitonic and interband transitions of 2D and 3D HOIPs correlate well with the energy separation between valence and conduction bands within a series. Bottom: Approach presented here, where the width (atom-atom distance) of the cation is varied.

was assessed by elemental analysis and powder XRD; in each case, XRD patterns for powder samples were consistent with the corresponding single-crystal structures (see Fig. S1, ESI $\dagger$; CCDC 1986784-1986789 and 1987208†). In all cases, we obtained $\mathrm{PbI}_{4}{ }^{2-}$ layers of corner-sharing octahedra separated by bilayers of the organic cations (Fig. 2). In all compounds, there is hydrogen bonding between the iodides and the ammonium groups, which is typical for $\mathrm{A}_{2} \mathrm{PbI}_{4}$ HOIP structures. Based on the offset of successive inorganic layers, we can categorize dF-PEA, PEA, dCl-PEA and dMe-PEA as near-Ruddlesden-Popper structure and dBr-PEA as monocation-near-Dion-Jacobson structures (see offset in Table S3, ESI $\dagger$ ). ${ }^{28}$

Thermogravimetric analysis of the four HOIPs based on 2-(3,5-disubstitutedphenyl)ethylammonium ions (see Fig. S2, ESI $\dagger$ ) shows two distinct weight losses: one begins at $c a .230{ }^{\circ} \mathrm{C}$, while our reference $(\mathrm{PEA})_{2} \mathrm{PbI}_{4}$ starts exhibiting weight loss at $200{ }^{\circ} \mathrm{C}^{12}$

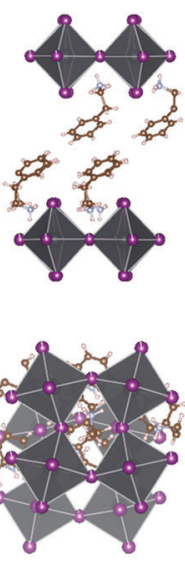

$(\mathrm{PEA})_{2} \mathrm{Pbl}_{4}$
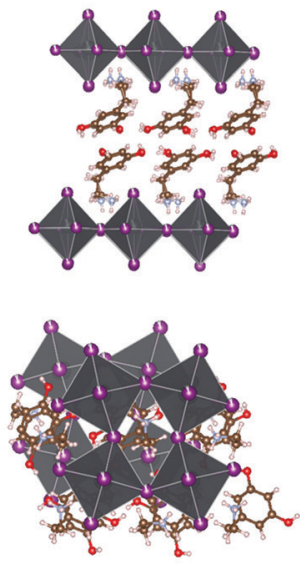

(dF-PEA) ${ }_{2} \mathrm{Pbl}_{4}$
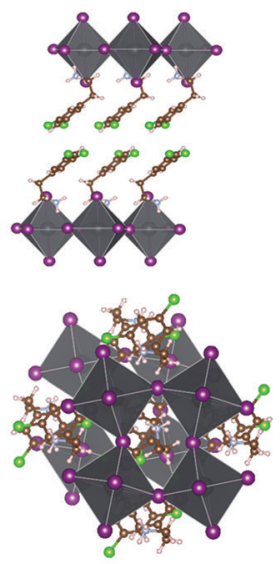

$(\mathrm{dCl}-\mathrm{PEA})_{2} \mathrm{Pbl}_{4}$
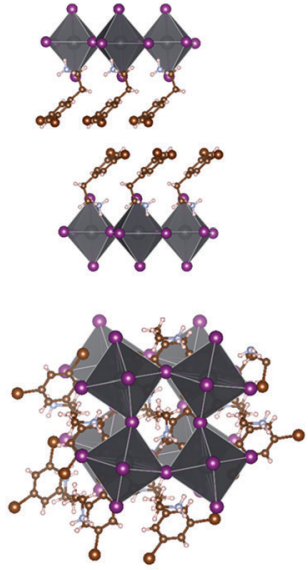

$(\mathrm{dBr}-\mathrm{PEA})_{2} \mathrm{Pbl}_{4}$
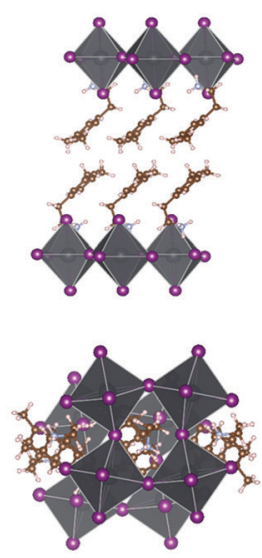

(dMe-PEA) ${ }_{2} \mathrm{Pbl}_{4}$

Fig. 2 Crystal structure of (dY-PEA) $\mathrm{Pbl}_{4}, \mathrm{Y}=\mathrm{H}, \mathrm{F}, \mathrm{Cl}, \mathrm{Br}, \mathrm{Me}$, viewed along the plane of the inorganic sheet and after $+90^{\circ}$ rotation around the long in-layer axis. The structure of $(\mathrm{PEA})_{2} \mathrm{Pbl}_{4}$ is taken from the literature. ${ }^{34}$ 

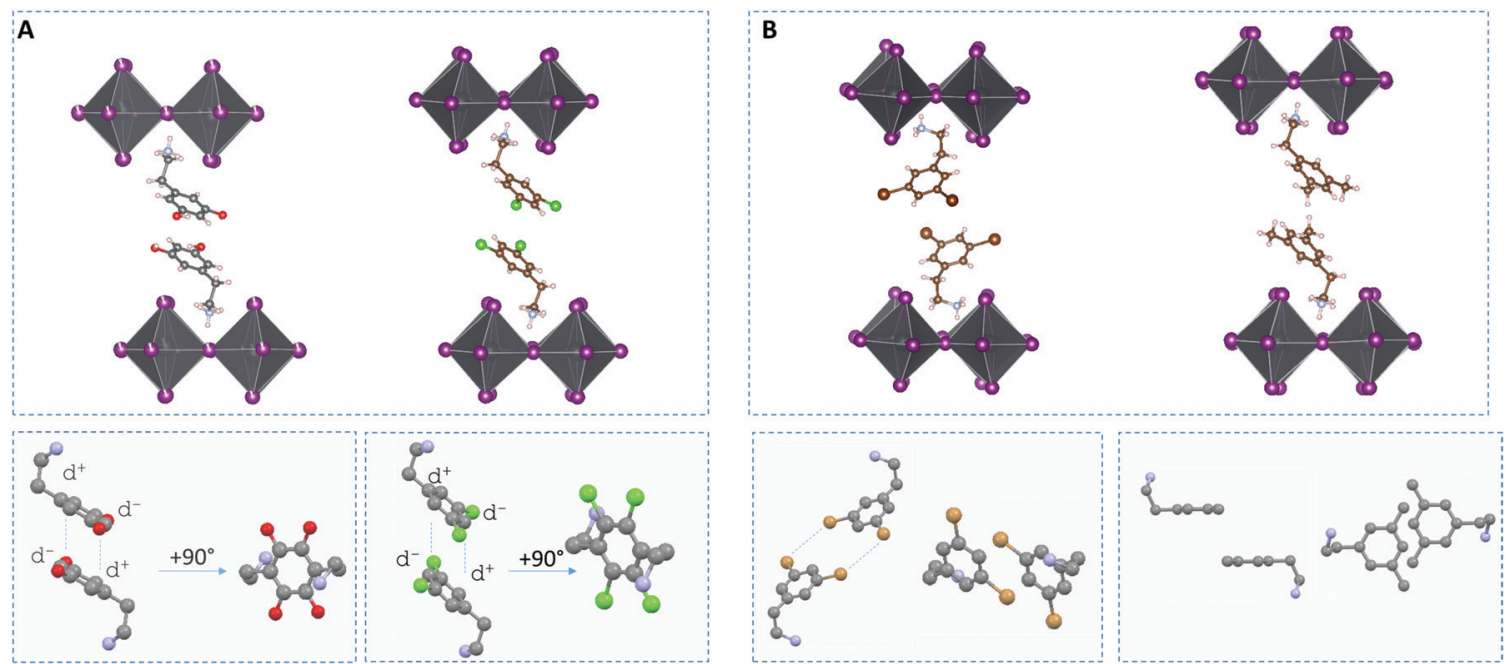

Fig. 3 Top: Partial crystal structure showing only two or three cations per four octahedra. Bottom: Cations showing the close approaches attributed to (A) dipole-dipole interaction (dY-PEA) ${ }_{2} \mathrm{Pbl}_{4}$, where $\mathrm{Y}=\mathrm{F}, \mathrm{Cl}$ and $(\mathrm{B}) \mathrm{Br} \cdots \mathrm{Br}$ and $\mathrm{CH}_{3} \cdots \mathrm{CH}_{3}$ van der Waals interactions in $(\mathrm{dBr}-\mathrm{PEA})_{2} \mathrm{Pbl}{ }_{4}(\mathrm{Br}-\mathrm{Br}$ distance $4.15 \AA$ ) and $(\mathrm{dMe}-\mathrm{PEA})_{2} \mathrm{Pbl}_{4}(\mathrm{C}-\mathrm{C}$ distance $3.94 \AA)$

This initial weight lost is likely due to the organic cation decomposition and loss, while the second period of weight loss is presumably due to the sublimation of the lead iodide.

Multiple cation-cation interactions can be found in these HOIPs single crystals (see Fig. S3-S5, ESI $\dagger$ ). For dF-PEA and dCl-PEA, the benzene rings from the two different organic layers are found to lay on top of each other. The distance between the centroid of one benzene to the plane made by another benzene is $3.343 \AA$ for $\mathrm{Y}=\mathrm{F}$ and $3.508 \AA$ for $\mathrm{Y}=\mathrm{Cl}$, which could arise from a dipole-dipole interaction between the two cations (see Fig. 3A). In the case of dBr-PEA, there is a close approach between the bromine atoms from the two layers. This may be due to a $\mathrm{Br} \cdots \mathrm{Br}$ van der Waals interaction (see Fig. 3B). A close approach between the methyl groups is also seen for dMe-PEA.

All compounds exhibited narrow linewidths for the photoluminescence feature characteristic of free exciton emission (see Fig. S5, ESI $\dagger$ ). Fig. 4A shows the Kubelka-Munk transformation of the diffuse reflectance of the different HOIP powders and indicate the presence of two distinct bands. The energy of the low-energy peak is assigned to the exciton band energy (see Fig. 4A). As expected, there is a linear relationship between the $\mathrm{Pb}-\mathrm{I}-\mathrm{Pb}$ angle and the exciton energy; the exciton band is red shifted by $c a$. $100 \mathrm{meV}$ from dBr-PEA to dF-PEA (see Fig. 4B). ${ }^{27}$ The relationships of $\mathrm{Pb}-\mathrm{I}-\mathrm{Pb}$ angle to the band gap in $3 \mathrm{D}$ HOIPs ${ }^{20-24}$ and to the exciton-band energy in $2 \mathrm{D}$ HOIPs $^{8,27-31}$ have been observed in many instances as stated before. It has been shown that, in 3D HOIPs, band gap significantly opens upon octahedral tilting, mainly as a result of a decrease of the overlap integral, resulting in reducing antibonding character, and thus stabilization, of the valence band maximum. ${ }^{21}$ Since trends in the exciton energy often closely follow those in the band gap, this rule can be extrapolated for the exciton energy of 2D HOIPs.

There is also a linear trend between the $\mathrm{Pb}-\mathrm{I}-\mathrm{Pb}$ angle and the width of the cation (see Fig. 4C). What emerges, based on these 5 compounds, is that, even if the reference compound (PEA, smallest cross-section size) does not follow the trend, we are able to show that the width of the cation is a fair indicator of the $\mathrm{Pb}-\mathrm{I}-\mathrm{Pb}$ angle in the HOIPs.
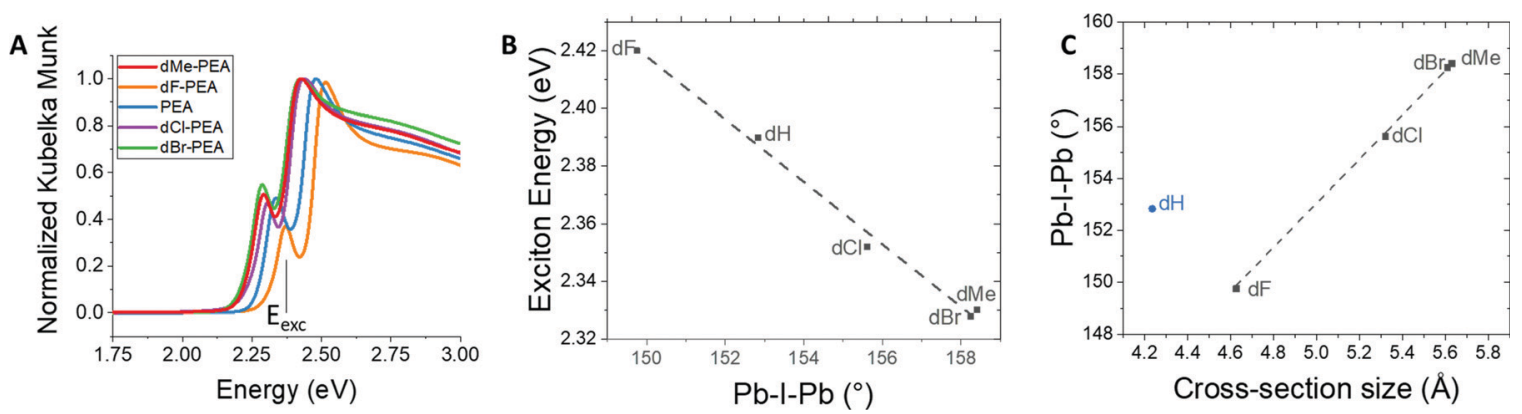

Fig. 4 (A) Normalized Kubelka-Munk transform of diffuse reflectance data for the different HOIPs powders (with exciton energy, $E_{\text {exc, }}$ indicated for the example of $\left.(\mathrm{dF}-\mathrm{PEA})_{2} \mathrm{Pbl}_{4}\right)$. (B) Relationship between the exciton energy and the $\mathrm{Pb}-\mathrm{I}-\mathrm{Pb}$ angle. (C) Relationship between the $\mathrm{Pb}-\mathrm{I}-\mathrm{Pb}$ bond angle and the width ( $Y-Y$ distance calculated from the MM2-minimized geometry of the cation in Chem3D) (dH is excluded from the fit). The width of dMe-PEA is calculated as the average of the three longest $\mathrm{H}-\mathrm{H}$ distances of the methyl. 

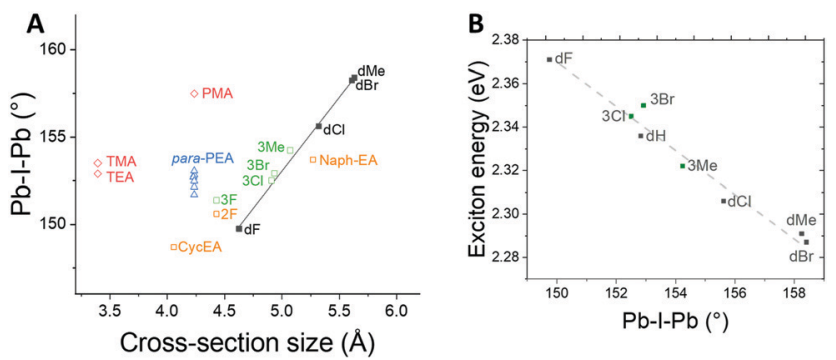

Fig. 5 Relationship between the $\mathrm{Pb}-\mathrm{I}-\mathrm{Pb}$ bond angle and the crosssection sizes $(Y-Y$ distance calculated from the MM2-minimized geometry in Chem3D). The $\mathrm{Pb}-\mathrm{I}-\mathrm{Pb}$ bond angle of 2F-PEA, 3F-PEA, 4F-PEA, 4Cl-PEA, 4Br-PEA, 4Ph-PEA, TMA, TEA, NEA, CycEA, PMA were calculated using the reported crystallographic data. The red diamonds are compounds that don't follow the hypothesis. The blue (para-PEA), black (dY-PEA), green (3Y-PEA) and yellow (others) compounds represent different families of compounds and follow the hypothesis.

In order to establish whether this trend holds true for cations other than 3,5-disubstituted PEAs, we extended the study to other families of cations (see Fig. 5). First, we synthesized meta-substituted phenylethylammonium-based HOIPs (3Y-PEA, where $\mathrm{Y}=\mathrm{Cl}, \mathrm{Br}, \mathrm{Me}$ ) and determined the structures. Another member of this series, $(3 \mathrm{~F}-\mathrm{PEA})_{2} \mathrm{PbI}_{4}$, has previously been reported; ${ }^{35}$ thus structural data are now available for both dY-PEA and 3Y-PEA families for the same set of substituents ( $\mathrm{Y}=\mathrm{F}, \mathrm{Cl}, \mathrm{Br}, \mathrm{Me}$ ). Again, the $\mathrm{Pb}-\mathrm{I}-\mathrm{Pb}$ bond angle increases with the width of the cation: the data points for the three new compounds essentially lie on the same line as those for the dY-PEA series, while the point for 3F-PEA compound still lies close to this line. Moreover, data for three newly synthesized compounds fit the same linear plot between the exciton energy and the $\mathrm{Pb}-\mathrm{I}-\mathrm{Pb}$ bond angle as the dY-PEA derivatives discussed above (see Fig. 5B).

We then examined additional structures available from literature reports. para-Substituted 2-phenylethylammoniumbased perovskites (in which the cross-section size is constant) have similar $\mathrm{Pb}-\mathrm{I}-\mathrm{Pb}$ bond angles $\left(\mathrm{A}_{2} \mathrm{PbI}_{4}\right.$ where $\mathrm{A}=\mathrm{PEA} 152.9^{\circ},^{34}$ 4F-PEA $151.5^{\circ},^{36}$ 4Cl-PEA $152.48^{\circ},{ }^{36}$ 4Br-PEA $152.15^{\circ}{ }^{36} 4 \mathrm{Ph}$-PEA $\left.153.1^{\circ},{ }^{31} 4 \mathrm{Cl}-\mathrm{Ph}-\mathrm{CH}\left(\mathrm{CH}_{3}\right) \mathrm{NH}_{3} 152.7^{\circ 37}\right)$, reinforcing the hypothesis that cross-section size is an important factor in determining the $\mathrm{Pb}-\mathrm{I}-\mathrm{Pb}$ bond angle, although the data points for these derivatives do not fall on the same line as the disubstituted and meta-substituted derivatives. $\mathrm{A}_{2} \mathrm{PbI}_{4}$ perovskites for $\mathrm{A}=\mathrm{TMA}^{38}$ and $\mathrm{TEA}^{39}$ cations (TMA $=2$-(2-thienyl)methylammonium, TEA = 2-(2-thienyl)ethylammonium), which have the same cross-section size but different alkyl length, have similar $\mathrm{Pb}-\mathrm{I}-\mathrm{Pb}$ bond angles to one another, but larger than one would expect based on the trend in the disubstituted and meta-substituted compounds. On the other hand, $\mathrm{Pb}-\mathrm{I}-\mathrm{Pb}$ angle and cross-section size data for $\mathrm{A}_{2} \mathrm{PbI}_{4}$ perovskites based on several other cations including 2-(naphth-2-yl)ethylammonium (NEA), ${ }^{34}$ 2-(1-cyclohexenyl)ethylammonium (CycEA), ${ }^{40}$ and 2-fluorophenylethylammonium (2F-PEA) ${ }^{41}$ do lie close to the line defined by the (dY-PEA) $)_{2} \mathrm{PbI}_{4}$ derivatives (and other $(3 \mathrm{Y}-\mathrm{PEA})_{2} \mathrm{PbI}_{4}$ derivatives) reported here.
There are cases of families of $2 \mathrm{D} \mathrm{A}_{2} \mathrm{PbI}_{4}$ structures reported in which the cross-section and $\mathrm{Pb}-\mathrm{I}-\mathrm{Pb}$ angle do not linearly correlate: (1) when the two layer of cations interpenetrate one another, instead of being separated in two sheets (parasubstituted PMAs); ${ }^{28}$ (2) when the 2D structure is not planar, but corrugated instead (as in the case of $\mathrm{A}=2$-(4-nitrophenyl)ethylammonium); ${ }^{42}$ and (3) when the core of the cation is much larger than that of 2-(phenyl)ethylammonium (pyrene and perylene derivatives). ${ }^{5,43,44}$

\section{Conclusion}

We report a total of 7 new 2D HOIPs containing 3,5-disubstitutedphenylethylammonium cations, dY-PEA ( $\mathrm{Y}=\mathrm{F}, \mathrm{Cl}, \mathrm{Br}, \mathrm{Me})$ and 3-substituted-phenylethylammonium cations, 3Y-PEA ( $\mathrm{Y}=\mathrm{Cl}$, $\mathrm{Br}, \mathrm{Me})$. We were able to demonstrate that, at least for some limited series of compounds, the width of the cation correlates with the distortion of the inorganic sheet through $\mathrm{Pb}-\mathrm{I}-\mathrm{Pb}$ bond angle variation, which in turn correlates with the exciton energy. We note that while the second of these correlations has been discussed in other systems and can be understood in terms of effects on the perovskite band structure, ${ }^{21}$ the first is purely an empirical observation. That is, the mechanism by which the cation width affects the bond angle is not clear, although, it is expected that changes in steric demands associated with variations of the cation width will affect the optimum packing in the interlayer region; these changes in packing may be accommodated by structural changes in both organic and inorganic portions of the structure. Given the complex energetic balance of interactions and the conformational flexibility of both the organic cations and the inorganic layers in these structures, the specific structural changes observed are not easily rationalized, as is underscored by the observed non-universality of the width/angle correlation. However, although width is not a universal factor determining the $\mathrm{Pb}-\mathrm{I}-\mathrm{Pb}$ angle and multiple other factors must likely be taken into account, the observation of this relation for at least some families of cations brings us closer to developing an understanding between the structure of the organic cation and the structure of the corresponding 2D HOIP. The deviations observed from the proposed relation may afford insight into other descriptors that could be looked at in the future.

\section{Conflicts of interest}

There are no conflicts of interest to declare.

\section{Acknowledgements}

This work was supported by NSERC (ES. D. Scholarship for MHT) and the AFOSR (FA9550-18-1-0499). We thank Khaled Al Kurdi for his help with thermal measurements and Ningxin Jiang, Dr Alexander Steiner and Tom Pickel for help with crystal measurement. This work was performed in part at the Georgia Tech Institute for Electronics and Nanotechnology, a member 
of the National Nanotechnology Coordinated Infrastructure (NNCI), which is supported by the National Science Foundation (Grant ECCS-1542174).

\section{References}

1 I. C. Smith, E. T. Hoke, D. Solis-Ibarra, M. D. McGehee and H. I. Karunadasa, A layered hybrid perovskite solar-cell absorber with enhanced moisture stability, Angew. Chem., Int. Ed., 2014, 53, 11232-11235.

2 J. Yan, W. Qiu, G. Wu, P. Heremans and H. Chen, Recent progress in 2D/quasi-2D layered metal halide perovskites for solar cells, J. Mater. Chem. A, 2018, 6, 11063-11077.

3 Y. Chen, Y. Sun, J. Peng, W. Zhang, X. Su, K. Zheng, T. Pullerits and Z. Liang, Tailoring organic cation of $2 \mathrm{D}$ air-stable organometal halide perovskites for highly efficient planar solar cells, Adv. Energy Mater., 2017, 7, 1700162.

4 D. H. Cao, C. C. Stoumpos, O. K. Farha, J. T. Hupp and M. G. Kanatzidis, 2D Homologous perovskites as light-absorbing materials for solar cell applications, J. Am. Chem. Soc., 2015, 137, 7843-7850.

5 C. Ma, D. Shen, T.-W. Ng, M.-F. Lo and C.-S. Lee, 2D Perovskites with short interlayer distance for high-performance solar cell application, Adv. Mater., 2018, 30, 1800710.

6 H. Lai, B. Kan, T. Liu, N. Zheng, Z. Xie, T. Zhou, X. Wan, X. Zhang, Y. Liu and Y. Chen, Two-dimensional RuddlesdenPopper perovskite with nanorod-like morphology for solar cells with efficiency exceeding 15\%, J. Am. Chem. Soc., 2018, 140, 11639-11646.

7 H. Tsai, W. Nie, J.-C. Blancon, C. C. Stoumpos, R. Asadpour, B. Harutyunyan, A. J. Neukirch, R. Verduzco, J. J. Crochet, S. Tretiak, L. Pedesseau, J. Even, M. A. Alam, G. Gupta, J. Lou, P. M. Ajayan, M. J. Bedzyk, M. G. Kanatzidis and A. D. Mohite, High-efficiency two-dimensional RuddlesdenPopper perovskite solar cells, Nature, 2016, 536, 312.

8 L. Mao, W. Ke, L. Pedesseau, Y. Wu, C. Katan, J. Even, M. R. Wasielewski, C. C. Stoumpos and M. G. Kanatzidis, Hybrid Dion-Jacobson 2D lead iodide perovskites, J. Am. Chem. Soc., 2018, 140, 3775-3783.

9 C. C. Stoumpos, D. H. Cao, D. J. Clark, J. Young, J. M. Rondinelli, J. I. Jang, J. T. Hupp and M. G. Kanatzidis, Ruddlesden-Popper hybrid lead iodide perovskite 2D homologous semiconductors, Chem. Mater., 2016, 28, 2852-2867.

10 S. Ahmad, P. Fu, S. Yu, Q. Yang, X. Liu, X. Wang, X. Wang, X. Guo and C. Li, Dion-Jacobson phase 2D layered perovskites for solar cells with ultrahigh stability, Joule, 2019, 3, 794-806.

11 M. Yuan, L. N. Quan, R. Comin, G. Walters, R. Sabatini, O. Voznyy, S. Hoogland, Y. Zhao, E. M. Beauregard, P. Kanjanaboos, Z. Lu, D. H. Kim and E. H. Sargent, Perovskite energy funnels for efficient light-emitting diodes, Nat. Nanotechnol., 2016, 11, 872.

12 H. Tsai, W. Nie, J.-C. Blancon, C. C. Stoumpos, C. M. M. Soe, J. Yoo, J. Crochet, S. Tretiak, J. Even, A. Sadhanala, G. Azzellino, R. Brenes, P. M. Ajayan, V. Bulović, S. D. Stranks, R. H. Friend, M. G. Kanatzidis and A. D. Mohite, Stable light-emitting diodes using phase-pure Ruddlesden-Popper layered perovskites, Adv. Mater., 2018, 30, 1704217.

13 M. E. Kamminga, G. A. de Wijs, R. W. A. Havenith, G. R. Blake and T. T. M. Palstra, The role of connectivity on electronic properties of lead iodide perovskite-derived compounds, Inorg. Chem., 2017, 56, 8408-8414.

14 K. Tanaka, T. Takahashi, T. Ban, T. Kondo, K. Uchida and $\mathrm{N}$. Miura, Comparative study on the excitons in lead-halidebased perovskite-type crystals $\mathrm{CH}_{3} \mathrm{NH}_{3} \mathrm{PbBr}_{3} \mathrm{CH}_{3} \mathrm{NH}_{3} \mathrm{PbI}_{3}$, Solid State Commun., 2003, 127, 619-623.

15 J. H. Noh, S. H. Im, J. H. Heo, T. N. Mandal and S. I. Seok, Chemical management for colorful, efficient, and stable inorganic-organic hybrid nanostructured solar cells, Nano Lett., 2013, 13, 1764-1769.

16 J. Xing, F. Yan, Y. Zhao, S. Chen, H. Yu, Q. Zhang, R. Zeng, H. V. Demir, X. Sun, A. Huan and Q. Xiong, High-efficiency light-emitting diodes of organometal halide perovskite amorphous nanoparticles, ACS Nano, 2016, 10, 6623-6630.

17 M. R. Filip, G. E. Eperon, H. J. Snaith and F. Giustino, Steric engineering of metal-halide perovskites with tunable optical band gaps, Nat. Commun., 2014, 5, 5757.

18 I. Borriello, G. Cantele and D. Ninno, Ab initio investigation of hybrid organic-inorganic perovskites based on tin halides, Phys. Rev. B: Condens. Matter Mater. Phys., 2008, 77, 235214.

19 G. E. Eperon, S. D. Stranks, C. Menelaou, M. B. Johnston, L. M. Herz and H. J. Snaith, Formamidinium lead trihalide: a broadly tunable perovskite for efficient planar heterojunction solar cells, Energy Environ. Sci., 2014, 7, 982-988.

20 C. C. Stoumpos and M. G. Kanatzidis, The renaissance of halide perovskites and their evolution as emerging semiconductors, Acc. Chem. Res., 2015, 48, 2791-2802.

21 C. Katan, N. Mercier and J. Even, Quantum and dielectric confinement effects in Lower-Dimensional Hybrid Perovskite Semiconductors, Chem. Rev., 2019, 119, 3140-3192.

22 L. Pedesseau, D. Sapori, B. Traore, R. Robles, H.-H. Fang, M. A. Loi, H. Tsai, W. Nie, J.-C. Blancon, A. Neukirch, S. Tretiak, A. D. Mohite, C. Katan, J. Even and M. Kepenekian, Advances and promises of layered halide hybrid perovskite semiconductors, ACS Nano, 2016, 10, 9776-9786.

23 J. L. Knutson, J. D. Martin and D. B. Mitzi, Tuning the band gap in hybrid tin iodide perovskite semiconductors using structural templating, Inorg. Chem., 2005, 44, 4699-4705.

24 T. Umebayashi, K. Asai, T. Kondo and A. Nakao, Electronic structures of lead iodide based low-dimensional crystals, Phys. Rev. B: Condens. Matter Mater. Phys., 2003, 67, 155405.

25 S. Meloni, G. Palermo, N. Ashari-Astani, M. Grätzel and U. Rothlisberger, Valence and conduction band tuning in halide perovskites for solar cell applications, J. Mater. Chem. A, 2016, 4, 15997-16002.

26 R. Prasanna, A. Gold-Parker, T. Leijtens, B. Conings, A. Babayigit, H.-G. Boyen, M. F. Toney and M. D. McGehee, Band gap tuning via lattice contraction and octahedral tilting in perovskite materials for photovoltaics, J. Am. Chem. Soc., 2017, 139, 11117-11124.

27 L. Mao, C. C. Stoumpos and M. G. Kanatzidis, Two-dimensional hybrid halide perovskites: principles and promises, J. Am. Chem. Soc., 2019, 141, 1171-1190. 
28 M.-H. Tremblay, J. Bacsa, B. Zhao, F. Pulvirenti, S. Barlow and S. R. Marder, Structures of $\left(4-\mathrm{Y}^{-} \mathrm{C}_{6} \mathrm{H}_{4} \mathrm{CH}_{2} \mathrm{NH}_{3}\right)_{2} \mathrm{PbI}_{4}$ $\{\mathrm{Y}=\mathrm{H}, \mathrm{F}, \mathrm{Cl}, \mathrm{Br}, \mathrm{I}\}$ : tuning of hybrid organic inorganic perovskite structures from Ruddlesden-Popper to DionJacobson limits, Chem. Mater., 2019, 31, 6145-6153.

29 L. Mao, Y. Wu, C. C. Stoumpos, M. R. Wasielewski and M. G. Kanatzidis, White-light emission and structural distortion in new corrugated two-dimensional lead bromide perovskites, J. Am. Chem. Soc., 2017, 139, 5210-5215.

30 L. Mao, P. Guo, M. Kepenekian, I. Spanopoulos, Y. He, C. Katan, J. Even, R. D. Schaller, R. Seshadri, C. C. Stoumpos and M. G. Kanatzidis, Organic cation alloying on intralayer A and interlayer $\mathrm{A}^{\prime}$ sites in 2D hybrid Dion-Jacobson lead bromide perovskites $\left(\mathrm{A}^{\prime}\right)(\mathrm{A}) \mathrm{Pb}_{2} \mathrm{Br}_{7}$, J. Am. Chem. Soc., 2020, 142(18), 8342-8351.

31 N. R. Venkatesan, A. Mahdi, B. Barraza, G. Wu, M. L. Chabinyc and R. Seshadri, Enhanced yield-mobility products in hybrid halide Ruddlesden-Popper compounds with aromatic ammonium spacers, Dalton Trans., 2019, 48, 14019-14026.

32 Z. Xu, D. B. Mitzi, C. D. Dimitrakopoulos and K. R. Maxcy, Semiconducting perovskites $\left(2-\mathrm{XC}_{6} \mathrm{H}_{4} \mathrm{C}_{2} \mathrm{H}_{4} \mathrm{NH}_{3}\right)_{2} \mathrm{SnI}_{4}(\mathrm{X}=\mathrm{F}$, $\mathrm{Cl}, \mathrm{Br})$ : Steric Interaction between the organic and inorganic layers, Inorg. Chem., 2003, 42, 2031-2039.

33 D. B. Mitzi, C. D. Dimitrakopoulos and L. L. Kosbar, Structurally tailored organic-inorganic perovskites: optical properties and solution-processed channel materials for thin-film transistors, Chem. Mater., 2001, 13, 3728-3740.

34 K.-Z. Du, Q. Tu, X. Zhang, Q. Han, J. Liu, S. Zauscher and D. B. Mitzi, Two-dimensional lead(II) halide-based hybrid perovskites templated by acene alkylamines: crystal structures, optical properties, and piezoelectricity, Inorg. Chem., 2017, 56, 9291-9302.

35 J. Hu, I. W. H. Oswald, S. J. Stuard, M. M. Nahid, N. Zhou, O. F. Williams, Z. Guo, L. Yan, H. Hu, Z. Chen, X. Xiao, Y. Lin, J. Huang, A. M. Moran, H. Ade, J. R. Neilson and W. You, CCDC 1893384: Experimental crystal structure determination, 2019, DOI: 10.5517/ccdc.csd.cc21k6xr.

36 D. B. Straus, N. Iotov, M. R. Gau, Q. Zhao, P. J. Carroll and C. R. Kagan, Longer cations increase energetic disorder in excitonic 2D hybrid perovskites, J. Phys. Chem. Lett., 2019, 10, 1198-1205.

37 C.-K. Yang, W.-N. Chen, Y.-T. Ding, J. Wang, Y. Rao, W.-Q. Liao, Y.-Y. Tang, P.-F. Li, Z.-X. Wang and R.-G. Xiong,
The first 2D homochiral lead iodide perovskite ferroelectrics: [R-and $S$-1-(4-chlorophenyl)ethylammonium $]_{2} \mathrm{PbI}_{4}$, Adv. Mater., 2019, 31, 1808088.

38 X.-H. Zhu, N. Mercier, A. Riou, P. Blanchard and P. Frère, $\left(\mathrm{C}_{4} \mathrm{H}_{3} \mathrm{SCH}_{2} \mathrm{NH}_{3}\right)_{2}\left(\mathrm{CH}_{3} \mathrm{NH}_{3}\right) \mathrm{Pb}_{2} \mathrm{I}_{7}$ : non-centrosymmetrical crystal structure of a bilayer hybrid perovskite, Chem. Commun., 2002, 2160-2161, DOI: 10.1039/B205543K.

39 H. Dammak, S. Elleuch, H. Feki and Y. Abid, Synthesis, crystal structure, vibrational spectra, optical properties and theoretical investigation of a two-dimensional selfassembled organic-inorganic hybrid material, Solid State Sci., 2016, 61, 1-8.

40 D. G. Billing and A. Lemmerer, Poly[bis[2-(1-cyclohexenyl)ethylammonium]di- $\mu$-iodo-diodoplumbate(II)], Acta Crystallogr., Sect. C: Cryst. Struct. Commun., 2006, 62, m269-m271.

41 J. Hu, I. W. H. Oswald, S. J. Stuard, M. M. Nahid, N. Zhou, O. S. Williams, Z. Gui, L. Yan, H. Hu, Z. Chen, X. Xiao, Y. Lin, J. Huang, A. M. Moran, H. Ade, J. R. Neilson and W. You, CCDC 1893383: Experimental crystal structure determination, 2019, DOI: 10.5517/ccdc.csd.cc21k6wq.

42 M.-H. Tremblay, F. Thouin, J. Leisen, J. Bacsa, A. R. Srimath Kandada, J. M. Hoffman, M. G. Kanatzidis, A. D. Mohite, C. Silva, S. Barlow and S. R. Marder, $(4 \mathrm{NPEA})_{2} \mathrm{PbI}_{4}(4 \mathrm{NPEA}=$ 4-nitrophenylethylammonium): structural, NMR, and optical properties of a $3 \times 3$ corrugated $2 \mathrm{D}$ hybrid perovskite, J. Am. Chem. Soc., 2019, 141, 4521-4525.

43 Since the PEA compounds does not fit on the same plot of $\mathrm{I}-\mathrm{Pb}-\mathrm{I}$ angle $v s$. cross-section as other derivatives (dF-PEA is larger than PEA but has a smaller $\mathrm{Pb}-\mathrm{I}-\mathrm{Pb}$ bond angle; Fig. 2) we looked at other characteristics of the cations. Interestingly, the increase of the $\mathrm{Pb}-\mathrm{I}-\mathrm{Pb}$ angle correlates with the polarizability of $\mathrm{Ar}-\mathrm{H}$ (i.e., that of the disubstituted phenyl ring minus the ethylammonium chain, see ref. 44 and Fig. S6, ESI $\dagger$ ). Using this indicator, the PEA and dF-PEA are in the right order, showing that multiple factors influences the $\mathrm{Pb}-\mathrm{I}-\mathrm{Pb}$ bond angle; however, overall, this plot also shows some scatter and some anomalies (e.g., dMe-PEA and dCl-PEA have similar polarizabilities but quite different bond angles).

44 R. Bosque and J. Sales, Polarizabilities of solvents from the chemical composition, J. Chem. Inform. Comput. Sci., 2002, 42, 1154-1163. 